\title{
Metaphor and Comprehension for ESL
}

\author{
Yuqing Xu \\ Department of Foreign Language Studies, Xiamen University Tan Kah Kee College, Zhangzhou, Fujian, \\ 363105, China \\ xuyuqing@xujc.com
}

Keywords: Metaphor, Comprehension, ESL

\begin{abstract}
The research on metaphor comprehension has a long history. Metaphor research was analyzed by researchers from different views such as Grice, Searle, Glucksberg. The paper first summarizes some of the research views on comprehending metaphors, then moves to explore the distinctive factors affecting metaphor comprehension for EFL students and then gives some suggestions for college English reading teaching.
\end{abstract}

\section{Introduction}

We live in a world of metaphors. Metaphors exist in our daily lives and in literary works. We can easily find metaphors in daily conversations, songs, advertisements, essays, poems, novels, and movies, for example, computer virus; You are my sunshine; Love is oxygen. (you get too much, it gets you high; not enough and you will die); Internet; the drug of the young, etc. It has had a history of 2,000 years since people did research on metaphors. From ancient Greek to now, researchers got a lot of papers and books published on metaphors. Researchers in the $20^{\text {th }}$ centuries such as Aristotle, J. Searle [1], H. P. Grice [2], Glucksberg [3, 4] and George Lakoff [5] are some of the famous ones. Recently, the research on metaphor is more considered as an interdisciplinary research which combines with psychology, philosophy, linguistics, and cognitive science. $A$ is $B$ is one of the most typical forms of metaphors and is the most widely researched by researchers. The present paper mainly focuses on the $A$ is $B$ form or predicative metaphors. The paper tries to explore the following questions: How do EFL comprehend figurative language? Is the process of comprehending metaphoric sentences similar to literal sentences? What factors may hinder students from comprehending metaphors?

\section{Metaphor}

Metaphor is a kind of comparison. It compares two things of different classes, and often contains an implied meaning. Ortony [6] considers that metaphors are often used to convey some concrete or difficult concepts. He implies that metaphors are used to fill the gap between the concept and word. Our everyday conceptual system is structured by a system of metaphor, including most abstract concepts.

Metaphors consist of three main parts: topic, vehicle and ground. The vehicle is something which carries information and is what is predicted of the topic. The ground, unlike the other two is not explicitly stated in a metaphor, is the implied similarity between tenor and vehicle; take sentence (1) for an example:

(1) She is a Rose.

This is a metaphor. The topic of this metaphor is she, the vehicle is rose. The ground is the similar features of she and rose. To get the implied meaning of the sentence, comprehender usually uses the topic and vehicle to infer the ground of the metaphor. In sentence (1), comprehender gets the implied meaning: she is as beautiful as a rose. Obviously, metaphor comprehension relies on the comprehender's knowledge on the topic and vehicle, and the ability to infer the ground of the metaphor. Among all, grounds are found to be as effective as (and sometimes even more effective than) topic or vehicles as recall cues for the sentences [7]. 


\section{Literature Review}

In the research of $20^{\text {th }}$ century, one of the old explanations on metaphor comprehension is Grice's theory. Grice suggests that comprehender comprehends metaphors through a series of stages. Firstly, the comprehender recognizes the literal sentence is not true. Secondly, the comprehender rejects its literal meaning and thinks of its possible meaning. Thirdly, the comprehender comprehends the implied or metaphoric meaning of the sentence. Grice explained the process of comprehending metaphor based on his Cooperative Principle which is composed of four maxims: The maxim of Quality (do not say what you believe to be false); the maxim of Quantity (make your words as informative as is required but do not make your words more informative than is required; The maxim of Relevance (make your contribution relevant); The maxim of Manner. Thus, as one kind of indirect speech, metaphor violates the maxims of quality; the comprehender first recognizes that the sentence is not literally true. Then, guided by the convention of quality, comprehender rejects the literal meaning of the sentence and tries to search for another possible meaning. Finally, the comprehender changes the sentence into an implicit similarity statement.

His explanation was accepted and applied by J. Searle. He studies and adopts Grice's cooperative principle theory to explain metaphor comprehension, suggesting that it takes comprehender multistage to finish the process of metaphor comprehension. Comprehender rejects the literal interpretation of a metaphor in order to search for the metaphoric meaning of the sentence. Both of their ideas mean that comprehender understands the literal interpretation of utterance before understanding its metaphorical interpretation, which implies that metaphors should always be taken more time to understand than literal ones. Metaphoric meaning is optional in that it comes to comprehend only when comprehender finds the literal meaning is inappropriate.

Another argument proposed by Glucksberg and Keysar. They argue that metaphors may be viewed as class-inclusion statement, take sentence (2) as an example:

(2) My job is a jail.

To interpret the sentence, comprehender must retrieve the lexical representations of the nouns and judge whether the class-inclusion relation is applied in the sentence appropriately or not.

"Glucksberg and Keysar suggest that the term jail belongs not to just one but to several different superordinate categories. It belongs to the category of punishments, including related notions of fines, tickets, and spankings. It is a member of the category of buildings, which also includes hotels, hospitals, and dormitories. It also may be considered a member of a category that does not have a conventional name but includes situation that are regarded as unpleasant, confining, or stifling. It is this latter category that may include the term job." (Carroll 2000)

They argue that even the literal meanings of words vary with their context. Metaphors also require a selective activation of information form the lexicon. They explained with sentences (3) and (4):

(3) The container held the apples.

(4) The container held the cola.

The word container is used in the above two sentences. In order to understand the sentence, comprehender retrieves the meaning of container and selects its appropriate representations to make the sentence sound reasonable. The comprehender may interpret container as something like a basket for sentence (3), while something like a bottle or cup for sentence (4). So, Glucksberg and Keysar's think that while comprehending metaphors, the comprehenders usually retrieve information from lexicon first, and then select the appropriate features of the lexicon. As Ortony (1993) [8] wrote, "Glucksberg propose that metaphors are class inclusion statements and are understood as such in the normal course of language comprehension."

Glucksberg keeps his opinion and further develops it, he uses sentence (5) to explain:

(5) My lawyer is a shark.

According to Glucksberg, this sentence is a regular class-inclusion assertion, my lawyer is the topic, and shark is the vehicle in the statement. To make the sentence sensible, comprehender needs to associate the common features of the topic and vehicle. While retrieving the lexical meaning of shark in the statement, comprehender may think of the features of a shark-fast swimmer, has fins, 
has sharp teeth, has leathery skin, has gills, vicious, predatory, aggressive, and tenacious. Then the comprehender compares the features of lawyer with shark. A lawyer is not likely associated with features of fast swimming, having fins, sharp teeth, leathery skin and grills in this sentence. And it is most likely to be vicious, since My lawyer is a shark is closer to My lawyer is vicious. Thus, metaphorical properties of sharks vicious, predatory, aggressive, and tenacious are attributed to My lawyer, but the literal properties of shark fast swimmer, has fins, has sharp teeth, has leathery skin, has gills-are not attributed to My lawyer.

However, Glucksberg's view of class-inclusion also causes controversy. Kintsch [9] argues that "Glucksberg's discussion fairly summarizes the empirical evidence on metaphor comprehension, but is incomplete in one important way: how do we know what is a superordinate-category level and what is a basic-level property?” He argues that Glucksberg's intuitive choice of the right features of shark's vicious creatures in My lawyer is a shark rather than features of fish are unsatisfactory enough.

Nonetheless, it cause disputes among linguists with regard to the views of Grice, Searle and Glucksberg. According to the recent research results, Grice and Searle's view has already been proved false. "There exists a considerable and convincing body of research in cognitive psychology and cognitive science that indicates that people understand metaphors in much the same way as they understand literal sentences." Cacciari \& Glucksberg [10], Gibbs [11, 12], Kintsch [13]. The widely accepted view believes that metaphors are easy to comprehend as literal sentences as there are no essential processing differences between metaphors and literal sentences. Whether they are metaphorical or literal ones, we tend to make analogy between metaphorical languages and literal ones while comprehending, rather than depending on literal languages or adopting deliberate reasoning skills.

\section{Metaphor Comprehension for EFL Students}

The recent studies on metaphors interpretation convince many researchers that the process of understanding metaphorical statements is automatic and is the way we do literal statements. Comprehender's knowledge and context facilitate the metaphors interpretation. Here comes the question: How about metaphor comprehension by EFL? Is the way of comprehending metaphors the same as literal statements for them? Are there any factors influencing their metaphorical interpretation?

Metaphor expressions (6), (7), (8), (9) used in this part are chosen from College English Reading Course 3 [14].

(6) Black was not a color on my mother; it was a shield that made her invisible. (p.25)

(7) I am a rope in a tug of war. (p.32)

(8) We are Oreos, they say, black on the outside, white within. (p.31).

(9) Even if the lasagna is major league, it might be even nicer just to be left ALONE sometimes. (p.3)

In the process of teaching, most freshmen are found to be easy to understand sentence (6) but not (7), (8) and (9). When asked, students say that since there are no new words in sentence (6) and they are familiar with the topic and vehicle in the sentence. Students know that the vehicle shield means something that use to cover, which greatly help them infer the ground, i.e. black is a cover, which helps them successfully understand the meaning of the metaphor: Black was not just a skin color on my mother; it like a shield that covers my mother, which makes her feel unexisted. When come to sentences (7), (8) and (9), students have difficulties; they say they are not familiar with the topic or vehicle such as tug of war, Oreos, lasagna, major league. If without the help of dictionaries or teachers they have difficulty in getting the meaning of the sentences.

Cultural differences between Chinese and western ones are also a factors affecting students' metaphor comprehension. Provided that they have had the knowledge of the topic and vehicle of in sentences (6), (7), (8) and (9), students can better understand sentences (6), (7) than sentences (8) and (9). In sentences (6) and (7), both cultures have the words of shield and tug of war: shield and tug of war in English while dunpai and bahe in Chinese. The common conception makes Chinese 
students understand the meaning of the sentence more easily. While different conceptions bring obstacles for students to understand metaphors, like Oreos, lasagna, major league in sentences (8) and (9). When meeting the English word Oreos (chocolate cookie with white cream filling), they take much time to understand the metaphorical meaning even though they are very familiar with the Chinese name of chocolate cookie Ao Li Ao. The sentence should be understood like this: The middle class blacks like Oreos cookies, which are black outside, white within. Likewise, it takes time for them to understand sentence (9) since major league contains cultural factors: Either of the two principal groups of professional baseball teams in the United States; the most important league in any sport, especially baseball. We cannot find the counterpart of major league in Chinese words so it takes time for students to figure out the meaning of sentence (9): Even if the lasagna is delicious or first-class, it might be even nicer just to be left ALONE sometimes.

As for English as a second language learners, especially for average learners, comprehending metaphorical expressions is not an easy one. Comprehending metaphorical expressions requires not only learners' mastery of words but cultural comprehension sometimes. To improve the ability of comprehending metaphorical expressions, students firstly need to conquer the barrier of words. Then for a better understanding the implied meaning of the sentences, it is important to learn the cultural differences between the two cultures. For teachers, it is important to notice students the metaphorical expressions use in the text while teaching. It is also a skill for teachers to help students understand an even apply metaphorical expressions especially in reading and writing courses.

\section{Conclusion}

The process of metaphor comprehension is made up of a set of stages is already proved false by recent linguistic research results. Researchers today consider that the process of comprehending metaphors is an automatic one and is as easy as literal statements. Certainly, there are more complex metaphors such as literary metaphors. It may take more time to understand those difficult ones as understand difficult literal statements. The metaphors that researchers focus on are mainly simple form $A$ is $B$, which is also the most frequently used in daily communications. Based on recent researchers' views, comprehenders are capable of understanding metaphors like literal sentences they do. As for the EFL students, however, the process of metaphor comprehension is more of a controlled one since it is affected not only by the knowledge of the topic and vehicle but the cultural factors. The process of metaphor comprehension for EFL students needs to do more research.

\section{References}

[1] J. R. Searle, Metaphor and Thought, Cambridge University Press, Cambridge, 1979.

[2] H. P. Grice, Syntax and semantics, 3 (1975) 41-58.

[3] S.Glucksberg, B.Keysar, Psychological Review, 97(1990) 3-18.

[4] S.Glucksberg, Current Directions in Psychological Science, 7(1998) 39-43.

[5] G. Lakoff, Metaphor and Thought (2nd edition), Cambridge University Press, Cambridge, 1992.

[6] A, Ortony, Educational Theory, 25 (1975) 45-53.

[7] Carroll, David W, Psychology of Language, Foreign Language Teaching and Research Press, Beijing, 2000.

[8] A, Ortony, Metaphor and Thought, Cambridge University Press, Cambridge, 1993.

[9] W. Kintsch, Psychonomic Bulletin \& Review, 7 (2000)257-266.

[10] Cacciari, C. \& Glucksberg, S. Understanding figurative language, in: M. A.Gernsbacher (Eds.), Handbook of psycholinguistics, Academic Press, San Diego, 1994. 
[11] R.W.Gibbs, Jr: Figurative thought and figurative language, in: M.A.Gernsbacher (Eds.), Handbook of psycholinguistics, Academic Press, San Diego, 1994, pp.441-446.

[12] R.W.Gibbs, Jr, Evaluating contemporary models of figurative language understanding. Metaphor and Symbol. 16(2001) 317-333.

[13] W. Kintsch, \& AR.Bowles, Metaphor and Symbol, 17 (2002) 249-262.

[14] Y.F.Ke, College English (New Edition) Reading and Writing Book 3, Shanghai Foreign Language Education Press, Shanghai, 2002. 